\title{
Intoxicação espontânea por Baccharis coridifolia em bovinos $^{1}$
}

\author{
Daniel R. Rissi ${ }^{2}$, Raquel R. Rech², Rafael A. Fighera², Didier Q. Cagnini ${ }^{3}$, \\ Glaucia D. Kommers ${ }^{4}$ e Claudio S.L. Barros ${ }^{4 *}$
}

\begin{abstract}
Rissi D.R., Rech R.R., Fighera R.A., Cagnini D.Q., Kommers G.D. \& Barros C.S.L. 2005. [Spontaneous Baccharis coridifolia poisoning in cattle.] Intoxicação espontânea por Baccharis coridifolia em bovinos. Pesquisa Veterinária Brasileira 25(2):111-114. Departamento de Patologia, Universidade Federal de Santa Maria, 97105-900 Santa Maria, RS, Brazil. E-mail: claudioslbarros@uol.com.br

Two outbreaks of Baccharis coridifolia poisoning in cattle in southern Brazil are described. Cases occurred when stressed, hungry and thirsty cattle brought from pastures free of $B$. coridifolia were placed into pastures heavily infested by this poisonous plant. In the two outbreaks morbidity was $21.73 \%$ and $22.51 \%$ and lethality was virtually $100 \%$. Clinical signs included mild bloat, instability of hind limbs, muscle tremors, dry muzzle, dry feces or diarrhea, polydipsia and restlessness. Consistent necropsy findings included dehydration, large amounts of ruminal fluid, reddening and erosions of the mucosae of the forestomachs. Degeneration and necrosis of the lining epithelium of the forestomachs and of lymphoid tissue were the main histopathological changes encountered.
\end{abstract}

INDEX TERMS: Poisonous plants, Baccharis coridifolia, Asteraceae, diseases of cattle, pathology.

RESUMO.- São descritos dois surtos de intoxicação por Baccharis coridifolia em bovinos no Sul do Brasil. Os casos ocorreram quando bovinos estressados, com fome e sede, provenientes de pastagens livres de $B$. coridifolia, foram introduzidos em locais altamente infestados por essa planta tóxica. A morbidade nos dois surtos foi de $21,73 \%$ e $22,51 \%$, e a letalidade foi virtualmente de $100 \%$. Os sinais clínicos incluíam discreto timpanismo, instabilidade dos membros pélvicos, tremores musculares, focinho seco, fezes secas ou diarréicas, polidipsia e inquietação. Alterações presentes em todas as necropsias incluíam desidratação, grande quantidade de conteúdo líquido no rúmen, avermelhamento e erosões da mucosa dos pré-estômagos. As principais alterações histopatológicas encontradas foram degeneração e necrose do revestimento epitelial dos pré-estômagos e do tecido linfóide.

\footnotetext{
${ }^{1}$ Recebido em 6 de dezembro de 2004.

Aceito para publicação em 2 de fevereiro de 2005.

Realizado com apoio financeiro do Programa de Apoio a Núcleos de Excelência (PRONEX), Proc. CNPq 661069/1997.

2 Programa de Pós-Graduação em Medicina Veterinária, Área de Concentração em Patologia Veterinária, Centro de Ciências Rurais, Universidade Federal de Santa Maria (UFSM) 97105-900, Santa Maria, RS, Brasil.

3 Bolsista de Iniciação Científica do PIBIC/UFSM.

${ }^{4}$ Departamento de Patologia, UFSM. *Autor para correspondência. Email: claudioslbarros@uol.com.br
}

TERMOS DE INDEXAÇÃO: Plantas tóxicas, Baccharis coridifolia, Asteraceae, doenças de bovinos, patologia.

\section{INTRODUÇÃO}

Baccharis coridifolia DC. (Asteraceae) é uma planta tóxica dióica (Fig. 1) que ocorre no Rio Grande do Sul, Santa Catarina, Paraná e São Paulo, onde é conhecida popularmente como "mio-mio", e

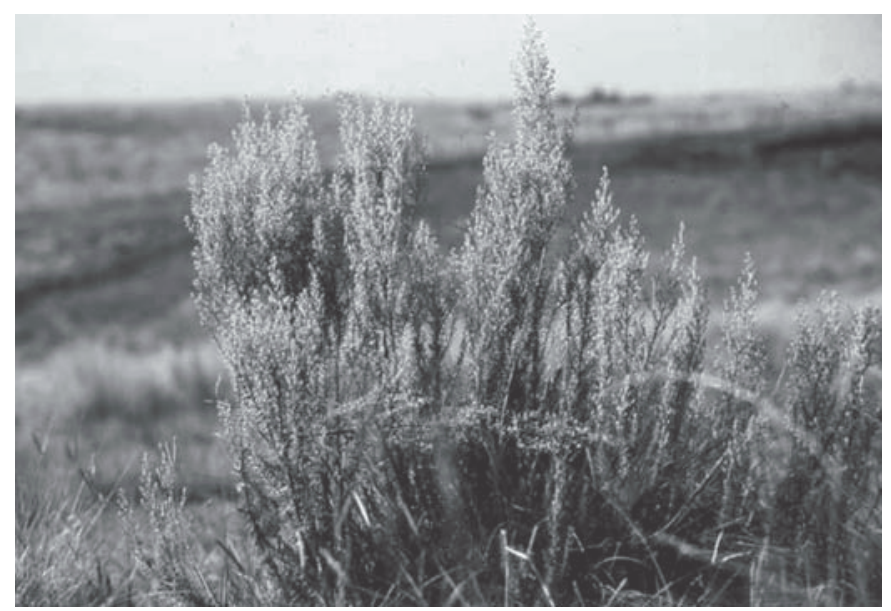

Fig. 1. Bacharis coridifolia é uma planta dióica que atinge altura de 50$80 \mathrm{~cm}$ e tem folhas lineares de $1,5-5 \mathrm{~cm}$ de comprimento. $O$ período de brotação é a primavera e a floração ocorre no outono. 
em grandes áreas do Uruguai e norte da Argentina, onde é denominada romerillo (Barros 1998). A intoxicação natural afeta principalmente bovinos, menos freqüentemente ovinos e raramente equiinos (Barros 1998). Bovinos que ingerem $B$. coridifolia desenvolvem doença aguda entre 5 e 30 horas do início da ingestão e morrem entre 3 e 23 horas após o início dos primeiros sinais clínicos (Tokarnia \& Döbereiner 1975, Barros 1998, Varaschin et al. 1998). Os animais apresentam anorexia, timpanismo discreto ou moderado, instabilidade dos membros pélvicos, tremores musculares, focinho seco, descarga ocular serosa, fezes secas ou diarréicas, salivação excessiva, polidipsia, vocalização, respiração laboriosa e rápida, taquicardia e inquietação (Tokarnia \& Döbereiner 1975, Barros 1998, Varaschin et al. 1998). Embora a planta seja mais tóxica durante a fase de floração (outono), as perdas de bovinos são mais comuns nos meses de primavera (setembro a novembro), durante o período de brotação da planta (Barros 1998). Doses de 0,25-0,50 g/ $/ \mathrm{kg}$ da planta em floração causam a morte de bovinos, enquanto, no período de brotação, são necessários $2 \mathrm{~g} / \mathrm{kg}$ para produzir o mesmo efeito (Tokarnia \& Döbereiner 1975). As lesões induzidas pela ingestão de $B$. coridifolia incluem necrose do epitélio gastrintestinal (principalmente nos pré-estômagos) e do tecido linfóide.

Apesar de existirem vários relatos verbais de intoxicações por $B$. coridifolia, e o quadro clínico ter sido reproduzido em diversas espécies como bovinos (Tokarnia \& Döbereiner 1975, Varaschin et al. 1998), ovinos (Tokarnia \& Döbereiner 1976), eqüinos (Costa et al. 1995) e coelhos (Döbereiner et al. 1976, Rodrigues \& Tokarnia 1995), não há documentações detalhadas de surtos espontâneos da toxicose em bovinos, exceto pela menção de casos espontâneos feitos por ocasião do primeiro trabalho de reprodução experimental da intoxicação por $B$. coridifolia no Brasil (Tokarnia \& Döbereiner 1975). Julgamos, portanto, oportuna a documentação da ocorrência espontânea dessa toxicose em bovinos, devido à sua importância econômica no Sul do país.

O objetivo desse trabalho é descrever dois surtos espontâneos de intoxicação por B. coridifolia no estado do Rio Grande do Sul que resultaram na morte de 82 bovinos e apresentar os dados epidemiológicos, clínicos, de necropsia e histopatológicos desses surtos.

\section{MATERIAL E MÉTODOS}

Os dados epidemiológicos e clínicos foram obtidos através de visitas às fazendas onde ocorreram os casos de intoxicação, designadas Propriedades A e B. Dois bovinos de cada propriedade foram necropsiadas e fragmentos de rúmen, retículo, omaso, abomaso, intestino, linfonodos e encéfalo foram coletados, fixados em formol a $10 \%$, processados e corados pela técnica de hematoxilina e eosina (HE) para exame histopatológico. Na Propriedade B, um bovino foi sacrificado in extremis para necropsia.

\section{RESULTADOS}

\section{Epidemiologia}

No final do mês de outubro de 1986, 230 vacas de 3 anos de idade foram trazidas de uma fazenda onde os campos eram livres de Baccharis coridifolia, e agrupados com outros 200 bovinos na Propriedade A, localizada em Rosário do Sul, onde havia acentuada infestação pela planta no pasto. As 430 vacas foram submetidas à palpação retal para diagnóstico de gestação após terem sido mantidas em um piquete sem acesso a água e com baixa quantidade e qualidade de pasto por 15 horas. Os animais foram então liberados, pela tarde, em um pasto da Propriedade A, altamente infestado por $B$. coridifolia. As mortes começaram na manhã do dia seguinte, e, dentro de 72 horas, 50 vacas haviam morrido. A identificação dos brincos revelou que somente as vacas oriundas da propriedade onde não existia mio-mio tinham sido afetadas.

Em meados de setembro de 2004, 151 novilhas de 1 ano de idade foram transportadas de caminhão de uma pastagem cultivada com aveia e azevém para outro local. A viagem durou aproximadamente 90 minutos, e as novilhas foram soltas em um piquete de 11 ha, onde pernoitaram; havia água à vontade, mas a pastagem era escassa. Os animais ficaram no local por 15 a 20 horas, quando novamente foram transportados, por aproximadamente uma hora, até uma invernada de 350 ha (Propriedade B) localizada em outro município. Nessa invernada havia uma população de 94 novilhas (79 de 3 anos e 15 de 2 anos de idade). Os bovinos foram observados novamente 36 horas após terem sido introduzidos na Propriedade B, quando 19 novilhas foram encontradas mortas. Nas 24 horas seguintes, mais 13 novilhas morreram. A identificação pelos brincos revelou que apenas as novilhas de um ano, recentemente introduzidas na propriedade, foram afetadas. $O$ campo estava altamente infestado por $B$. coridifolia.

\section{Sinais clínicos}

Os animais de ambos os surtos apresentaram sinais clínicos similares, que incluíam timpanismo leve a moderado, instabilidade dos membros pélvicos, tremores musculares, focinho seco, fezes secas ou diarréicas, polidipsia e inquietação. $O$ gado afetado eventualmente assumia decúbito esternal, seguido de decúbito lateral e morte em poucas horas até 3 dias após ter sido introduzido nas pastagens infestadas por B. coridifolia.

\section{Patologia}

Os achados de necropsia incluíam desidratação, grande volume de conteúdo líquido no rúmen e vários graus de avermelhamento, edema e erosões na mucosa dos pré-estômagos, principalmente rúmen e retículo, em todos os casos. Em dois bovinos foi observada hiperemia da mucosa do abomaso e intestino e, em um caso, o conteúdo intestinal estava tingido de sangue. Os linfonodos mesentéricos estavam intumescidos, úmidos e vermelhos nos dois bovinos necropsiados da Propriedade A. Lesões pouco específicas como hemorragias endocárdicas acentuadas no ventrículo esquerdo foram observadas em todos os casos. As lesões histológicas incluíam alterações degenerativas e necróticas no revestimento epitelial do rúmen e retículo em todos os casos e necrose de folículos linfóides de linfonodos nos dois casos da Propriedade A. As lesões no epitélio estratificado dos pré-estômagos consistiam principalmente de encurtamento das pregas do rúmen. Em algumas áreas da mucosa, havia leve edema intercelular multifocal que separava as células epiteliais. Nessas regiões, múltiplas células demonstravam degeneração hidrópica e observavam-se vários 


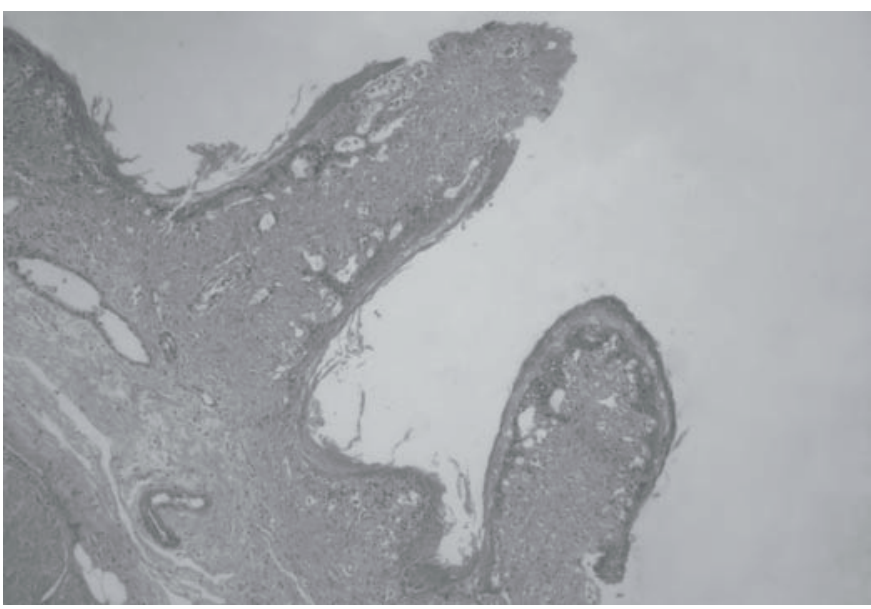

Fig. 2. Intoxicação espontânea por Baccharis coridifolia em bovino. Vacuolização e necrose do epitélio das papilas do rúmen. As partes das papilas desprovidas de epitélio são recobertas por densos aglomerados de bactérias cocóides. HE, obj. 4 .

corpúsculos de Civatte (apoptose). Na maioria das pregas ruminais as células epiteliais apresentavam citoplasma intensamente eosinofílico e cariorrexia. Essas áreas de necrose deixavam as papilas parcialmente (erosão) ou totalmente (ulceração) desnudas e recobertas por restos celulares e densos aglomerados de bactérias cocóides (Fig. 2). Em algumas áreas, neutrófilos ocorriam isoladamente entre as células epiteliais da mucosa (exocitose) ou, menos freqüentemente, formando agregados na forma de microabscessos de Munro. Na junção do epitélio com a lâmina própria havia múltiplas fendas, algumas com neutrófilos íntegros e degenerados no seu interior. Os vasos linfáticos da lâmina própria estavam bastante distendidos e repletos de neutrófilos degenerados, trombos de fibrina e, ocasionalmente, acúmulos de bactérias cocóides. Os vasos sangüíneos da lâmina própria estavam repletos de sangue. Infiltrado neutrofílico e hemorragias na lâmina própria ( 2 casos) ou transmural ( 1 caso) também foram observados. Necrose do tecido linfóide foi observada em linfonodos e em agregados linfóides; nos linfonodos, lesões necróticas moderadas envolviam os folículos, sugerindo envolvimento de linfócitos B. Nos linfonodos mesentéricos dos bovinos da propriedade $\mathrm{B}$, grande número de bactérias associadas a células inflamatórias ocorriam nos vasos linfáticos (Fig. 3).

\section{DISCUSSÃO}

Vários fatores foram considerados para determinar que a ingestão de Baccharis coridifolia foi a causa das mortes de bovinos descritas aqui. Nas duas propriedades, os bovinos afetados vieram de locais onde a planta tóxica não ocorria e, em ambos os casos, foram mantidos por várias horas sob situações de estresse, como jejum e sede; além disso, todos os bovinos foram introduzidos em locais altamente infestados por B. coridifolia. Esses fatores são bem conhecidos e considerados de risco para favorecer o consumo de mio-mio. Bovinos nascidos e criados em propriedades onde existe $B$. coridifolia não ingerem a planta (Barros 1998). Tipicamente, a toxicose ocorre quando bovinos nativos de áreas indenes são transferidos para pastagens infestadas por

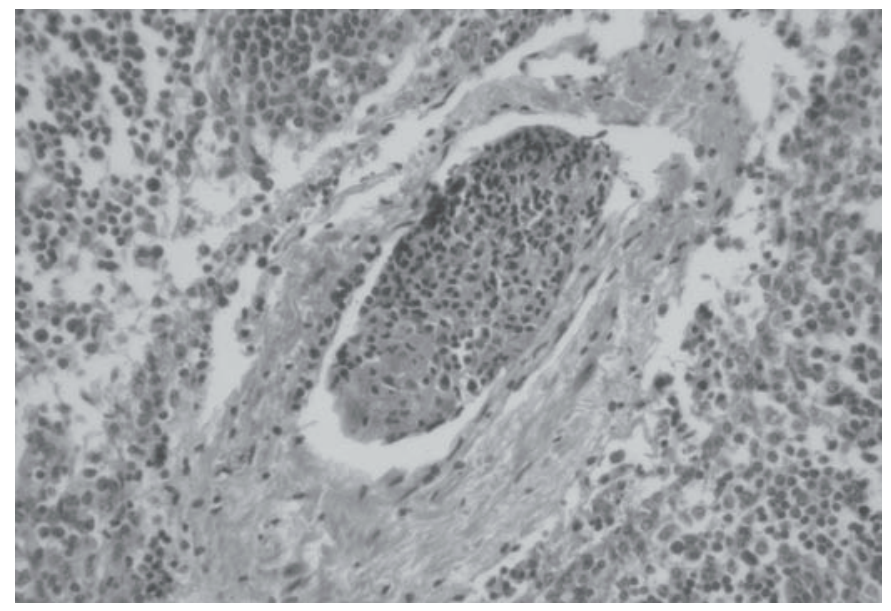

Fig. 3. Vaso repleto de células inflamatórias e aglomerados de bactérias cocóides em linfonodo, na intoxicação espontânea por Baccharis coridifolia em bovino. HE, obj. 25

mio-mio. O risco de ocorrência da intoxicação aumenta consideravelmente se, enquanto transportados, os bovinos forem submetidos a situações de estresse, como fadiga, fome ou sede (Tokarnia \& Döbereiner 1975, Barros 1998). Embora a perda de animais pela intoxicação por $B$. coridifolia seja muito importante, é difícil avaliar seguramente a prevalência da doença. A maioria dos casos não é relatada aos laboratórios de diagnóstico veterinário, pois os proprietários e veterinários reconhecem a condição e prontamente programam medidas para seu controle.

A mortalidade é muito alta e pode alcançar até $80 \%$ em bovinos transportados para áreas infestadas por mio-mio sem ter sido previa e adequadamente descansados, alimentados e dessedentados. Nos dois surtos relatados neste artigo, a morbidade foi $21,73 \%$ e $22,51 \%$ e a letalidade foi virtualmente de $100 \%$. Nestes casos, outra evidência circunstancial que aponta B. coridifolia como a causa das perdas é a doença aguda que seguiu a introdução dos animais que desconheciam a planta em pastos infestados e o não desenvolvimento de doença nos animais nativos da área. Existem várias hipóteses que explicam os motivos pelos quais animais nascidos e criados em pastos $\operatorname{com} B$. coridifolia nunca ingerem a planta (Barros 1998). Essas teorias são, entretanto, difíceis de provar ou refutar. Os sinais clínicos, achados de necropsia e histopatológicos relatados nestes casos foram idênticos aos descritos previamente nas intoxicações experimentais por B. coridifolia (Barros 1998, Varaschin et al. 1998).

A causa da morte nos casos de intoxicação por $B$. coridifolia ainda não foi esclarecida, porém, considerando as lesões no epitélio do rúmen e o grande volume de líquido no seu interior, desidratação e desequilíbrio de eletrólitos podem ter papel importante na morte dos bovinos, de maneira semelhante ao que ocorre na acidose ruminal. $\mathrm{O}$ achado de grandes aglomerados de bactérias sobre o revestimento desnudado do epitélio do rúmen e nos linfonodos, mesmo nos animais eutanasiados para necropsia, sugere que a septicemia possa atuar na patogênese. É interessante notar que essa associação com bactérias já foi observada na intoxicação por B. megapotamica (Tokarnia et al. 1992). 
Todas as partes da planta são tóxicas, porém as sementes e flores contêm altas concentrações dos princípios tóxicos (Jarvis et al. 1988, Jarvis et al. 1996), que foram identificados como tricotecenos macrocíclicos: roridina A e E, miotoxina A, B, C e D, miopitoceno A e B e verrucarol. Tais substâncias são produzidas por fungos do gênero Myrothecium, principalmente $M$. roridum e $M$. verrucaria, que habitam o solo e se desenvolvem próximo às raízes de B. coridifolia (Busam \& Habermehl 1982, Habermehl et al. 1985). Experimentos com B. coridifolia em coelhos (Rodrigues \& Tokarnia 1995) e em bovinos (Varaschin et al. 1998) sugerem que os espécimes femininos da planta são muito mais tóxicos e isso foi confirmado por análises químicas mensais de plantas femininas e masculinas realizadas durante um ano (Jarvis et al. 1996). Tricotecenos macrocíclicos, como os encontrados em $B$. coridifolia, são fitotóxicos para outras espécies da planta e foram usados como arma química para destruição de colheitas (Jarvis et al. 1996). Tricotecenos macrocíclicos similares, extraídos de outra espécie de Baccharis (B. megapotamica var. weirii), foram capazes de destruir células neoplásicas em linfomas de células B em ratos em uma investigação sobre plantas com atividade antiblástica (Kupchan et al. 1977); isso pode explicar a necrose linfóide encontrada em alguns dos animais afetados pela intoxicação. A reprodução experimental (Tokarnia et al. 1992) e a observação de surtos espontâneos (Driemeier et al. 1999) da intoxicação por B. megapotamica já foi descrita em bovinos.

\section{REFERÊNCIAS}

Barros C.S.L. 1998. Livestock poisoning by Baccharis coridifolia, p.569572. In: Garland T. \& Barr A.C. (ed) Toxic Plants and Other Natural Toxicants. CAB International, Wallingford. 576p.

Busam L. \& Habermehl G.G. 1982. Accumulation of mycotoxins by Baccharis coridifolia: a reason for livestock poisoning. Naturwissenschaften 69:391393.

Costa E.R., Costa J.N., Armien A.G., Barbosa J.D. \& Peixoto P.V. 1995.
Intoxicação experimental por Baccharis coridifolia (Compositae) em equïinos. Pesq. Vet. Bras. 15:19-26.

Döbereiner J., Resende A.M.L. \& Tokarnia C.H. 1976. Intoxicação experimental por Baccharis coridifolia em coelhos. Pesq. Agropec. Bras. 11:2735.

Driemeier D., Cruz C. \& Loretti A.P. 1999. Intoxicação por Baccharis megapotamica var. weirii (Compositae) em bovinos do Rio Grande do Sul. 9o Enapave, Belo Horizonte, p.143. (Resumo)

Habermehl G.G., Busam L., Hydel P., Mebs D., Tokarnia C.H., Döbereiner J. \& Sproul M. 1985. Macrocyclic trichothecenes: causes of livestock poisoning by the Brazilian plant Baccharis coridifolia. Toxicon 23:731745 .

Jarvis B.B., Midiwo J.O., Bean G.A., Aboul-Nasr M.B. \& Barros C.S.L. 1988. The mystery of trichothecene antibiotics in Baccharis species. J. Natural Prod. 4:736-744.

Jarvis B.B., Mokhtari-Rejali N., Schenkel E.P., Barros C.S.L. \& Matzembacher N.I. 1991. Trichothecenes mycotoxins from Brazilian Baccharis species. Phytochemistry 30:789-797.

Jarvis B.B., Wang S., Cox C., Varaschin M.S. \& Barros C.S.L. 1996. Brazilian Baccharis toxins: livestock poisoning and isolation of macrocyclic trichothecenes glucosides. Nat. Toxins 4:58-61.

Kupchan S.M., Strelman D.R., Jarvis B.B., Dailey R.J.Jr. \& Snenden A. 1977. Isolation of potent new antileukemic tricothecenes from Baccharis megapotamica. J. Org. Chem. 42:4221-4225.

Rodrigues R.L. \& Tokarnia C.H. 1995. Fatores que influenciam a toxidez de Baccharis coridifolia (Compositae): um estudo experimental em coelhos. Pesq. Vet. Bras. 15:51-69.

Tokarnia C.H. \& Döbereiner, J. 1975. Intoxicação experimental em bovinos por "mio-mio", Baccharis coridifolia. Pesq. Agropec. Bras. 10:79-97.

Tokarnia C.H., Döbereiner J. 1976. Intoxicação experimental em ovinos por "mio-mio", Baccharis coridifolia. Pesq. Agropec. Bras. 11:19-26.

Tokarnia C.H., Peixoto P.V., Gava A. \& Barros C.S.L. 1992. Intoxicação experimental por Baccharis megapotamica var. megapotamica e var. weirii (Compositae) em bovinos. Pesq. Vet. Bras. 12:19-31.

Varaschin M.S., Barros C.S.L. \& Jarvis B.B. 1998. Intoxicação experimental por Baccharis coridifolia (Compositae) em bovinos. Pesq. Vet. Bras. 18:6975 . 